\begin{abstract}
4.2. So sánh với các tác giả khác vê ảnh hưởng của vật liệu nha khoa lên chỉ số lâm sàng mô nướu quanh mão răng. Kết quả nghiên cứu của chúng tôi phù hợp với nghiên cứu của Nayer và cộng sự [4] khi so sánh giữa nhóm mão toàn sứ và nhóm sứ - kim loại được thực hiện từ 6 tháng đến 2 năm, cho thấy sự khác biệt không có ý nghĩa về các chỉ số mảng bám, chảy máu khi thăm khám và độ sâu túi. Nghiên cứu của Reitemeier [5] cũng cho thấy loại hợp kim và vật liệu chế tác mão không ảnh hưởng đến mức độ tích tụ mảng bám và sức khỏe của mô nha chu khi so sánh giữa các nhóm sau 1 năm gắn phục hình. Christensen [6], Jameel và cộng sự [7] khi so sánh mão toàn sứ zirconia với mão sứ - kim loại cũng cho kết luận không có sự khác biệt có ý nghĩa thống kê về ảnh hưởng lên mô nha chu của hai nhóm vật liệu. Nghiên cứu của chúng tôi cũng cho kết quả tương đồng với Al-Wahadni và cộng sự [8]; trong khi đó Gemalmaz và Ergin nhận thây phục hình bằng mão sứ ít tích tụ mảng bám hơn so với mão sứ - kim loại do đó cũng cần có thêm những nghiên cứu thời gian dài hơn để làm rõ về mối liên quan này. Nghiên cứu này và các tác giả $[7,8]$ cho thấy thói quen vệ sinh và mức độ quan tâm đến phục hình mão răng trong miệng của bệnh nhân có ảnh hưởng đến tình trạng mô nướu quanh phục hình. Việc hướng dẫn vệ sinh răng miệng cần được lặp lại liên tục trong mối lân điều trị và tái khám để đảm bảo thành công của phục hình mão sứ và sứ kim loại ở các bệnh nhân.
\end{abstract}

\section{KẾT LUÂ̂N}

Qua nghiên cứu trên cho thấy không có sự khác biệt về ảnh hưởng sứ và hợp kim lên chỉ số mô nướu quanh răng khi thực hiên phục hình mão răng. Hướng dẫn vệ sinh răng miệng cần được lặp lai liên tục trong mỗi lần điều trị và tái khám để đảm bảo thành công lâu dài phục hình mão sứ và sứ kim loại thực hiện trên bệnh nhân.

\section{TÀI LIÊU THAM KHẢO}

1. Nelson, S.K., J.C. Wataha, and P.E. Lockwoodc, "Accelerated toxicity testing of casting alloys and reduction of intraoral release of elements". The Journal of prosthetic dentistry, 1999. 81(6): p. 715-720.

2. Pierce, L.H. and $\mathbf{R}$. Goodkind, "A status report of possible risks of base metal alloys and their components". 1989. 62(2): p. 234-238.

3. Gristina, A.G.,"Biomaterial-centered infection: microbial adhesion versus tissue integration". Journal Science, 1987. 237(4822): p. 1588-1595.

4. Nayer, A., et al.,"An update on the effect of crown margin locations and materials on periodontal health". Dental journal, 2012. 58(3639): p. 3644.

5. Reitemeier, B., et al., "Effect of posterior crown margin placement on gingival health". The Journal of prosthetic dentistry, 2002. 87(2): p. 167-172.

6. Christensen, G., "Porcelain-fused-to-metal versus zirconia-based ceramic restorations". The Journal of the American Dental Association, 2009. 140(8): p. 1036-1039.

7. Jameel, A., A. Hasan, and S. Rashid, "An evaluation of association between crown margins \& materials with the periodontal health". JPDA, 2011. 20(03).

8. Al-Wahadni, A., Y. Mansour, and Y. Khader, "Periodontal response to all-ceramic crowns in general practice". International journal of dental hygiene, 2006. 4(1): p. 41-46.

\title{
KẾT QUẢ PHẪU THUÂ̂T NỐI THẦn KINH TRỤ DO VẾT THƯƠNG CỔ TAY
} Nguyễn Hữu Trọng*, Phạm Thị Việt Dung*, Tạ Thị Hồng Thúy*

\section{TÓM TẮT}

Mục tiêu: Mô tả đặc điểm lâm sàng và kết quả điều trị nối thần kinh trụ do vết thương cổ tay. Đối tượng và phương pháp: Mô tả loạt catrên 24 bệnh nhẩn có vêt thương cố tay với tổn thương thần kinh tru đước phấu thuât tai Khoa Phẫu thuâat tao hìnhBểnh viện đa khoa Xanh Pôn. Kết quả: 21 nam và 3 nữ, tuổi trung bình 41.67 tuổi (từ 18-82 tuổi). Cơ chế tổnthương thường gặp nhất là kính cắt 16/24 bệnh nhân $(66.67 \%)$, do dao $6 / 24$ bệnh nhân $(25 \%)$, cớ chế khác 2/24 bệnh nhân (8.33\%). Câu trúc giải phẫu

*Trường Đại học Y Hà Nội

Chịu trách nhiệm chính: Nguyễn Hữu Trọng

Email: nguyenhuutronghmu@gmail.com

Ngày nhận bài: 22/8/2021

Ngày phản biện khoa học: 20/9/2021

Ngày duyệt bài: 2/10/2021 tổn thương phối hợp cùng thân kinh trụ hay gặp nhất là gân gấp cổ tay trụ gặp 24/24 bệnh nhân (100\%). Tôn thương phối hợp cơ gấp cổ tay tru, thần kinh trụ, động mạch trụ (bộ ba trụ) gặp ở 18/24 bệnh nhẩn (75\%), tổn thương thần kinh giữa phối hợp gặp ở12/24 bệnh nhân (50\%). 100\% bệnh nhân được khâu nối thần kinh trụ thì đâuu theo kĩ thuật khâu bao nhóm bó.Tất cả được theo dõi đánh giá phục hồi chức năng thần kinh sau 6 tháng trở lên (trung bình 16 tháng). Kết quả phục hồi vận động tốt đạt 14/24 $(58.33 \%)$, kết quá phục hồi cảm giác tốt đạt $16 / 24$ $(66.67 \%)$. Kết luận: Tổn thương thần kinh trụ do vết thương cổ tay chủ yếu gây ra bởi vật sắc nhọn, vết thương tuy không dập nát hay khuyết phần mềm nhưng tổn thương phức tạp, nhiêuu cấu trúc giải phẫu kèm theo. Kĩ thuật khâu nối tận tận bao nhóm bó vẫn là phương pháp mang lại hiệu quả nhất. Tư khóa: Tổn thương thần kinh trụ, vết thương cổ tay. 


\section{SUMMARY \\ RESULTS ULNAR NERVE REPAIR INWRIST INJURIES}

Objective: The aim of this study was todescribe the clinical characteristics and evaluate the treatment results ulnar nerve repair in wrist injuries. Subjects and methods: The case series descriptive study of 24 patients with 24 ulnar nerves. Results: Including 21 males and 3 females, average age of 41.67 years (range:18-82 years). The most frequent mechanisms of injury were accidental glass lacerations 16/24 $(66.67 \%)$, knife wounds $6 / 24(25 \%)$, others $2 / 24$ $(8.33 \%)$. The most frequently injured structure with ulnar nerve was flexor carpi ulnaris 24/24(100\%). Combined flexor carpi ulnaris, ulnar nerve, ulnar artery (ulnar triad) injuries occurred in 18/24 (75\%), combined ulnar nerve and median nerve injuries occurred in 12/24 (50\%). Group fascicular repair was used in all patients. Follow up was performed for at least 6 months, with average of 16 months. Good sensory and motor recovery were reported respectively in 16/24(66.67\%) and 14/24 (58.33\%). Conclusion: Because ulnar nerve injuries in wrist were mainly caused by sharp objects, the wounds weren't crushed, but complicated with many injurred structures. Therefore, it was necessary to examine and evaluate carefully to avoid missing injuries. End to end group fascular repair in cases without nerve defect was still the most effective method .

Keywords: Ulnar nerve injury, wrist injury.

\section{I. ĐĂT VẤN ĐỀ}

Tổn thương đứt thần kinh ngoai vi là loại tổn thương thường gặp trong chấn thương, nguyên nhân thường do các vật sắc cắt gặp trong tai nạn sinh hoạt, lao động hoăc tai nạn giao thông. ở chi trên, tổn thương tại vùng cổtay chiếm tỷ lề cao vì vùng thường xuyên tiếp cận với các vật dụng lao động, sinh hoạt hàng ngày, đây cũng là vùng phản xạ chống đở bảo vệ cơ thể [1]. Điều trị khâu nối phục hồi đứt thần kinh ngoại vi là phẫu thuật khó.Với sự ra đời của kĩ thuật vi phẫu việc khâu nối thần kinh đã đạt được những bước tiến đáng kể, tuy nhiên kêt quả phục hồi chức năng tốt còn chưa cao [2]. Việt Nam là đất nước đang phát triển nên tai nạn lao động chiếm tỉ lệ còn cao. Trong đó, tổn thương thần kinh trụ không phải hiếm găp, di chứng để lại ảnh hưởng nhiều tới chức năng bàn tay nếu không được xử lý đúng. Vì vậy, bài báo này nhằm mục đích đánh giá đă̆c điểm lâm sàng và kết quả khâu nối thần kinh trụ do vết thương cổ tay.

\section{II. ĐỐI TƯợNG VÀ PHƯƠNG PHÁP NGHIÊN CỨU}

1.Đối tượng nghiên cứu: Gồm 24 bệnh nhân được chẩn đoán vết thương cổ tay có tổn thương thần kinh tru tại Khoa Phẫu thuât Tao hình - Bệnh viện Đa khoa Xanh Pôn từ 06/2016 đễn 06/2021.

\section{Phương pháp nghiên cứu}

2.1. Thiết kế nghiên cứu: Phương pháp nghiên cứu mô tả loạt ca, hồi cứu kết hợp tiến cứu.

\subsection{Quy trình phẫu thuật}

- Chuẩn bị bệnh nhân: Bệnh nhân nằm ngửa, dưới gây tê đám rối cánh tay, bộc lộ vết thương, sát khuẩn, trải toan.

- Mơ đường vào theo đường vêt thương hoăc mở rộng vết mổ theo đường zích zắc nếu cần thiết, bộc lộ, bóc tách rõ đoạn dây thần kinh bị tổn thương ra khỏi tổ chức xung quanh.

- Xác định và xử lý các tổn thương phối hợp như gân cớ, mạch máu, xương khớp.

- Khâu nối thần kinh: Dưới kính hiển vi hoặc kính lúp phóng đai.

+ Chuẩn bi hai đầu thần kinh bằng cách sử dụng dao hoặc kéo vi phẫu sắc cắt gọn hai đâu thần kinh tổn thương. Bóc tách bao ngoài một đoạn ngắn ở hai đầu tận, phẫu tích tỉ mỉ bộc iộ các nhóm bó thần kinh trụ tại cổ tay. Dựa vào tương quan kích thước các nhóm bó, hệ mạch máu trên bao ngoài dây thần kinh đề sắp xếp thẳng hàng các nhóm bó.

+ Gấp cổ tay 30 đô, đánh giá sức căng nếu nối trực tiếp,nếu hai đầu tận không áp vào nhau thì tiến hành ghép thần kinh.

+ Khâu hai mũi khâu giảm căng giúp 2 đầu thần kinh áp sát nhau, thực hiện các mũi khâu bao nhóm bó bằng chỉ nylon 9:0 để áp hai đầu tận. Mỗi nhóm bó ta đăt 2-3 mũi khâu. Tránh đặt nhiều mũi khâu tại mối nhóm bó vì nguy cơ gầy xơ seo. Thường tai vùng cổ tay có 2-4 nhóm bó thần kinh trụ, gồm 1 nhóm bó vận động và 1-2 nhóm bó cảm giác.

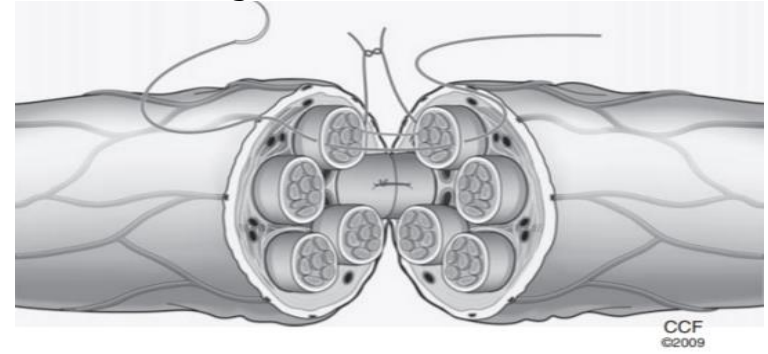

Hình 1. Kỹ thuật khâu bao nhóm bó trong tổn thương thần kinh ngoai vi.

- Sau khi phẫu thuật xong, bệnh nhân được nẹp bột cẳng bàn tay với cổ tay gấp 30 độ, cẳng tay được gấp khoảng 120 độ treo lên cổ, bột để trong 2-3 tuần.

- Sau mổ: Bênh nhân được theo dõi, đánh giá và hướng dẫn tập phục hồi chức năng theo hẹn.

2.3. Đánh giá và phân loại kết quả theo lâm sàng. Dánh giá kết quả phục hồi chức năng thần kinh trụ do vết thương cổ tay chủ yếu dựa 
vào chức năng cơ nội tại và cảm giác bàn tay. Trong nghiên cứu của chúng tôi sử dụng phân loại kết quả phục hồi chức năng vận động và cảm giác dựa trền tiêu chuẩn đánh giá thần kinh ngoại vi của BMRC(British Medical Research Council), với vận động được đánh giá từ mức M0-M5, cảm giác từ S0-S4.

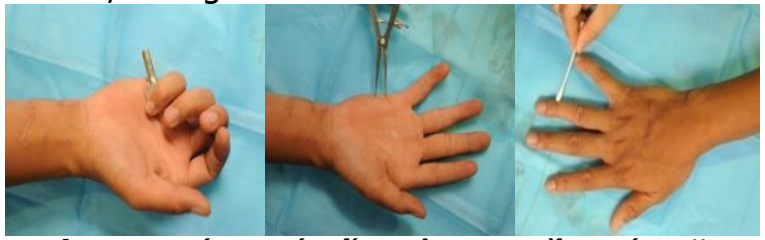

Hình 2. Đánh giá kết quả phục hồi chức năng bằng cách khám cảm giác theo vùng chi phối

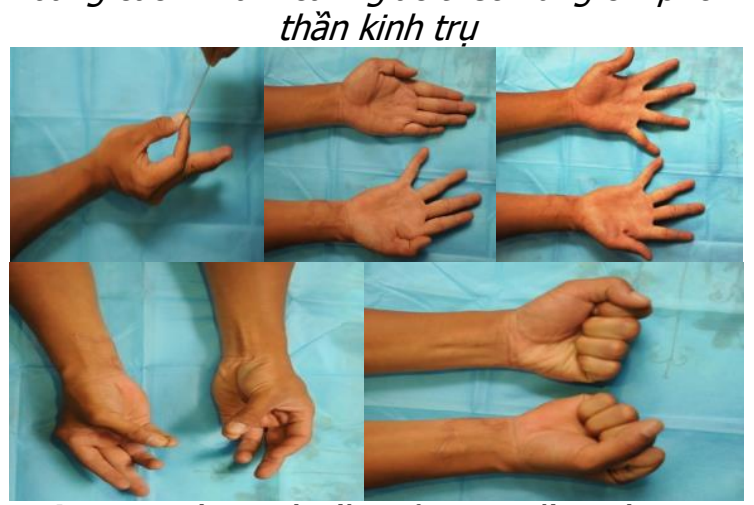

Hình 3. Đánh giá kết quả phục hồi chức năng vận đông bằng cách khám các động tác do thần kinh tru chi phối.

Trên cơ sở đánh giá như trên, dựa theo phân loại kết quả của BMRC và xác định phân loại kết quả như sau: ${ }^{2}$

- Tốt: Vận động đạt mức M4 hoặc M5, cảm giác đạt mức S3+ hoặc S4.

- Không tốt: Vận động đạt dưới mức M4, cảm giác đạt dưới mức S3+.

\section{KẾT QUẢ NGHIÊN CứU}

\section{Kết quả lâm sàng}

1.1. Đăc điểm đối tượng nghiên cứu. Có 24 bệnh nhân với 24 tổn thương thần kinh trụ do vết thương cổ tay được đánh giá. Trong đó có 21 nam và 3 nữ, tuổi trung bình 41.67 tuổi (từ 18-82 tuổi). Cơ chế tổn thương thường gặp nhất là kính cắt chiếm 16/24 bệnh nhân (66.67\%), do dao 6/24 bệnh nhân (25\%), cơ chế khác 2/24 bệnh nhân (8.33\%). Tay phải chiếm 14/24 bệnh nhân $(58.33 \%)$, tay trái chiếm $10 / 24$ bệnh nhân (41.67\%).

1.2. Đặc điểm tổn thương phối hợp. Tổn thương cẩu trúc giải phẫu phối hợp cùng thần kinh trụ hay gặp nhất là gân gấp cổ tay trụ gặp 24/24 (100\%). Tổn thương phối hợp cơ gấp cổ tay trụ, thần kinh trụ, động mạch trụ (bộ ba trụ) gặp ở 18/24 (75\%), tổn thương thần kinh giữa phối hợp gặp ở 12/24 (50\%). Trong số các dây thần kinh trụ bị tổn thương, có 4/24 (16.67\%) tổn thương thần kinh trụ bán phần, 20/24 (83.33\%) tổn thương thần kinh trụ hoàn toàn.

2. Kết quả khâu nối thần kinh trụ. Tất cả bệnh nhân đều được khâu nối tận tận bao nhóm bó, tại cổ tay thần kinh trụ có từ 2-4 nhóm bó, mỗi nhóm bó được khâu 2-3 mũi chỉ nilon9-0 ngay thì đầu. Thời gian theo dõi từ 6 đến 48 tháng, trung bình 16 tháng. Kết quả phục hồi vận động tốt gặp 14/24(58.33\%), kết quả phục hồi cảm giác tốt gặp ở 16/24(66.67\%).

Với những bệnh nhân tổn thương thần kinh trụ bán phần, tỷ lệ phục hồi chức năng cảm giác và vận động là $100 \%$. Trong các bệnh nhân tổn thương phối hợp kèm gân xương, không có bệnh nhân nào đạt kết quả phục hồi chức năng tốt vận động và cảm giác.

\section{BÀN LUÂN}

Mặc dù chỉ chiếm tỷ lệ nhỏ so với các vùng khác trong cơ thể, nhưng chi trên lại đóng vai trò chính trong lao động, sinh hoạt hàng ngày, đây cũng là vùng chông đõ̃, bảo vệ cơ thể. Đặc biệt vùng cổ tay chiếm tỷ lệ lớn trong các tổn thương chi trên. Trong nghiên cứu của chúng tôi, hai cơ chế tổn thương thần kinh trụ ở vết thương cổ tay hay găp nhất là do kính cắt chiếm 16/24bênh nhân $(66.7 \%)$, do dao chiếm 6/24(25\%), khổng gặp tổn thương thần kinh trụ trong tai nạn giao thông. Với 32 bênh nhân trong nghiên cứu của Kokkalis tỷ lệ vết thương do kính cắt vào tay $56.25 \%$, do bị chém là $18.75 \%$, do cưa vòng là $18.75 \%$ và do tổn thương hỏa khí là $6.25 \%$ [3]. Còn trong nghiên cứu của Chemnizt ở trẻ em và trẻ thanh thiếu với 34 bệnh nhân, cơ chế chủ yếu tổn thương thần kinh trụ do kính cắt chiêm $84,44 \%$, do lưỡi cưa là $4,44 \%$, do dao là $2.22 \%$. Cơ chế tổn thương dây thần kinh trụ trong các nghiên cứu chủ yếu do vật sắc gây nên kể cả ở độ tuổi lao động hay ở trẻ em có thể giải thích bởi phản xạ đưa tay lên chống đõ khi gặp nguy hiểm của cở thể người.

Mackinnon đã chứng minh rằng việc sửa chữa ngay thì đâu mang lại kết quả tốt hơn bởi khi ây cấu trúc giải phẫu còn rõ ràng, sự co rút của hai đầu cụt thần kinh còn ít [4]. Với những tổn thương sạch, không nhiều cấu trúc dập nát, đủ khối lượng phần mềm che phủ thì việc nối thì đầu sẽ được ưu tiên. Ngược lại, với những tổn thương nhiễm bẩn, dập nát, khuyết phần mềm che phủ, việc nối thần kinh nên được trì hoãn 
đến kì hai khi vết thương đã ổn định [5].Trong nghiên cứu này, cơ chế tổn thương do các vật sắc chiếm đa số, vết thương thường sắc gọn và không có khuyết phần mềm kèm theo, vì vậy tất cả tổn thương thần kinh đều được xử lý cùng thì với xử lý các tổn thương phối hợp.Trong nghiên cứu của chúng tôi, tỷ lệ tổn thương bộ ba thần kinh trụ, động mạch trụ, gân gấp cổ tay trụ gặp đến 18/24 (75\%) trong tổng các tổn thương thần kinh trụ nói chung. Điều này có thể giải thích bởi tại vị trí giải phẫu cổ tay, thần kinh trụ đi ở phía trong động mạch trụ với cơ gấp cổ tay trụ làm tùy hành, vậy nên, khi có tổn thương một trong ba cấu trúc trên, thì rất dễ xẩy ra tổn thương của hai cấu trúc còn lại. Tỷ lệ gặp tổn thương thần kinh giữa kèm theo chiếm 12/24 (50\%) tổng số bệnh nhân, đây làtỷ lệ rất cao. Điều này đòi hỏi các phẫu thuật viên phải thực sự thận trọng trong phẫu thuật vết thương cổ tay nhằm tránh bỏ sót tổn thương. Cần phẫu tích rộng, đảm bảo không có tổn thương thần kinhgiữa kèm theo bằng cách quan sát sự liên tục của thần kinhgiữa trên đường đi giải phẫu của nó. Trong nghiên cứu của chúng tôi, số lượng tổn thương xương không hay gặp, nguyên nhân của sự hiếm gặp này một phần bởi cơ chế tổn thương gây nên vết thương cổ tay trong nghiên cứu của chúng tôi chủ yếu là vết thương do vật sắc gây nên như mảnh kính võ hay dao.

về kĩ thuật nối thần kinh, theo lý thuyết, khâu bao nhóm bó sẽ đạt được kết quả tốt hơn so với kĩ thuật khâu bao ngoài đơn thuần bởi khả năng sắp xểp các bó vận động và cảm giác chính xác hơn. Tuy nhiên, việc bóc tách các nhóm bó sẽ tăng nguy cơ tổn thương hệ mạch nuôi dưỡng dẫn tới việc xơ hóa tại mối nối. Điều này giải thích cho việc tại sao trên thực tế kĩ thuật khâu bao ngoài thương đạt kết quả tương tự như khi sử dụng kĩ thuật khẩu bao nhóm bó [6]. Do đó, hiện nay cả hai kĩ thuật đều được áp dụng trong sửa chữa thần kinh ngoại vi bị tổn thương. Việc lựa chọn kĩ thuật nào phụ thuộc vào vị trí tổn thương, thời gian thực hiện phẫu thuật, tính chất sắp xếp các bó trong dây thần kinh. Ớ các vị trí tổn thương cao, nơi các dây thần kinh chứa nhiều bó sợi nên thực hiện kỹ thuật khâu bao ngoài, còn đối với các tổn thương thấp như vị trí cổ tay, các dây thần kinh chứa ít nhóm bó và các nhóm bó thần kinh đã phân loại theo chức năng riêng biệt, sử dụng kĩ thuật khâu bao nhóm bó được khuyến cáo [7].

So sánh kết quả đạt được trong nghiên cứu và các kết quả của các tác giả trong nước như Nguyễn Viết Ngọc dựa trên nghiên cứu xác định bó sợi cảm giác và vận động hay nghiên cứu của Kato $H$ [8] và cộng sự thẩy rằng.

\section{Kết quả M4 và M5 S3+ và S4}

Kato $\mathrm{H}$ và $\mathrm{CS}: 78 \% 78 \%$

Nguyễn Viết Ngọc: $72.5 \% \quad 77.5 \%$

Nguyễn Hữu Trọng: $58.33 \% \quad 66.67 \%$

Nhìn chung, kểt quả khâu nối trong nghiên cứu của chúng tôi thấp hơn so với kết quả khâu nối của hai tác giả trên. Nguyên nhân chủ chính theo tôi là do các tác giả sử dụng kích thích điện hay các nghiên cứu giải phẫu giúp cho việc xác định các bó vận động và cảm giác được chính xác hơn so với các bệnh nhân trong nghiên cứu của chúng tôi.

Bởi có rất nhiều yếu tố ảnh hưởng đến kết quả khâu nối thần kinh ngoại vi, nên việc tiên lượng kết quả phục hồi chức năng là vấn đề phức tạp. Đã có nhiều nghiên cứu trong nhiều thập kỷ gần đây, nhiều yếu tố đã được chứng minh có vai trò quan trọng trong kết quả khâu nối. Trong nghiên cứu phân tích của mình,Ajruisdựa vào các yếu tố độc lập để đánh giá kết quả phục hồi chức năng như tuổi, phân loại và vị trí tổn thương, các tổn thương phối hợp, thời gian phẫu thuật, kỹ thuật khâu nối. Trong đó, kết quả đạt được tốt đối với các trường hợp trẻ tuổi, tổn thương bán phần và vị trí tổn thương thấp, các tổn thương phối hợp nhẹ, việc sửa chữa thần kinh được thực hiện ngay trong xử lý vết thương cổ tay, khâu bao nhóm bó thần kinh với các tổn thương ở vùng cổ tay [2].

\section{KẾT LUÂ̂N}

Tổn thương thần kinh trụ do vết thương cổ tay trong nghiên cứu của chúng tôi thường gây bởi các vật sắc nên rất vết thương gọn, không khuyết phần mềm nhưng tổn thương thường phức tạp. Kỹ thuật khâu nối thần kinh trụ trực tiếp bao nhóm bó thì đầu vẫn là phương pháp điều trị hiệu quả và hạn chế di chứng do tổn thương thần kinh trụ.

\section{TÀI LIỆU THAM KHẢO}

1. Kevin C Chung, Hidemasa Yoneda. Severe upper extremity injury in the adult patient. Uptodate. Published online August 2021.

2. Ruijs ACJ, Jaquet J-B, Kalmijn $S$, Giele $H_{\text {, }}$ Hovius SER. Median and Ulnar Nerve Injuries: A Meta-Analysis of Predictors of Motor and Sensory Recovery after Modern Microsurgical Nerve Repair: Plast Reconstr Surg. 2005;116(2):484-494. doi:10.1097/01.prs.0000172896.86594.07

3. Kokkalis ZT, Efstathopoulos DG,
Papanastassiou ID, Sarlikiotis T,
Papagelopoulos PJ. Úlnar nerve injuries in Papagelopoulos PJ. Ulnar nerve injuries in
guyon canal: A report of 32 cases: Ulnar Nerve 
Repair in Guyon Canal. Microsurgery. 2012;32(4):296-302. doi:10.1002/micr.21951

4. S E Mackinnon. New directions in peripheral nerve surgery. Ann Plast Surg. 1989;22(3):257273. doi:10.1097/00000637-198903000-00013

5. Lee SK, Wolfe SW. Peripheral Nerve Injury and Repair. J Am Acad Orthop Surg. 2000;8(4):10.

6. M G Orgel. Epineurial versus perineurial repair of peripheral nerves. Clin Plast Surg. 1984;4:101-105.
7. Rowshan K, Jones NF, Gupta R. Current surgical techniques of peripheral nerve repair. Oper Tech Orthop. 2004;14(3):163-170. doi:10.1053/j.oto.2004.06.006

8. Kato H, Minami A, Kobayashi M, Takahara M, Ogino T. Functional results of low median and ulnar nerve repair with intraneural fascicular dissection and electrical fascicular orientation. ] Hand Surg. 1998;23(3):471-482. doi:10.1016/ S0363-5023(05)80465-4

\section{KHẢO SÁT TÌNH HÌNH MẮC BÊNH LÝ MŨI XOANG VÀ MộT Số YẾU Tố LIÊN QUAN ĐẾN KHẢ NĂNG TIẾP CÂN CÁC DICH VỤ KHÁM CHỮA BỆNH BÊ̂NH LÝ VÙNG MŨI XOANG Ở BỀNH NHÂN TỪ 18 TUỔI TRỞ LÊN TẠI HUYỆN MỸ TÚ, TỈNH SÓC TRĂNG NĂM 2020 - 2021}

\section{TÓM TẮT}

Mục tiêu: Xác định tỷ lệ mắc các bệnh lý mũi xoang và khả năng tiếp cân các dịch vụ khám chữa bệnh ở bệnh nhân từ 18 tuổi trở lên mắc bệnh lý vùng mũi xoang tại Huyên Mỹ Tú, Tỉnh Sóc Trăng, năm 2020 -2021. Đối tượng và phương pháp: Nghiên cứu mô tả cắt ngang trên 640 người dân từ 18 tuổi trở lên tại Huyện Mỹ Tú, Tỉnh Sóc Trăng từ tháng 512/2020. Kểt quả: Tỷ lệ mắc bệnh lý vùng mũi xoang là $27,5 \%$. Trong đó, bệnh viêm mũi dị ứng là 44,9\%, viêm mũi xoang cấp tính là $20,5 \%$, viêm mũi xoang mạn tính là $33,5 \%$, Polype mũi là $1,1 \%$. $75 \%$ ở mức đồ nhe. . Tỷ lế đối tướng nghiên cứu tiếp cân dich vu khám chữa bệnh các bệnh lý mũi xoang là $77,3 \%$. Yếu tố liên quan đến tỷ lệ tiếp cận các dịch vu khám chữa bệnh của người dân bao gồm: Nơi ở, khoảng cách đến CSYT gần nhất, mức độ mắc bệnh, loại hình bệnh mũi xoang. Kết luận: Tỷ lệ mắc bệnh mũi xoang tại huyên Mỹ Tú, tỉnh Sóc Trăng khá cao chiếm $27.5 \%$ số đối tượng tham gia nghiên cứu. Khả năng tiếp cận các dịch vu khám chữa bệnh liên quan đến nơi ở, khoảng cách đến cơ sở y tế gần nhất, mức độ mắc bệnh, loại hình bênh mũi xoang.

Tứ khóa: Bênh lý mũi xoang, tiếp cận dịch vụ khám chữa bệnh, dịch vụ y tế.

\section{SUMMARY \\ INVESTIGATING DISEASES RELATED TO SINONASAL REGION AND EVALUATING ASSOCIATING FACTORS THAT EFFECT THE ACCESSIBILITY OF ADULT PATIENTS TO APPROPRIATE TREATMENTS AT MY TU}

${ }^{1}$ Trường đại học Y dược Cần Tho

²Bênh viện Đa khoa Tỉnh Sóc Trăng

Chịu trách nhiệm chính: Nguyễn Triều Việt

Email: vietctho@gmail.com

Ngày nhận bài: 2/8/2021

Ngày phản biên khoa học: 25/8/2021

Ngày duyệt bài: 24/9/2021

\section{Nguyễn Triều Việt ${ }^{1}$, Triệu Sà Kinh ${ }^{2}$}

DISTRICT, SOC TRANG PROVINCE, 2020-2021

Objectives: to determine the prevalence of sinonasal diseases and to evaluate associating factors effecting the accessibility of adult patients to appropriate treatments at My Tu district, Soc Trang province, 2020-2021. Subjects and methods: A cross-sectional study was conducted from over 640 people aged 18 years and older in My Tu district, Soc Trang province. Results: The prevalence of diseases of nose and paranasal sinuses is $27,5 \%$. Among those diseaseas, allergic rhinitis made up the largest proportion with $44,9 \%$. The percentages of chronic rhinitis, acute rhiniti, nasal polyposis accounted for $33,5 \%, 20,5 \%, 1,1 \%$ respectively. $75 \%$ out of all patients was not in severe conditions. The figure of study subjects accessing medical examination and treatment services for nose and sinus diseases was $77,3 \%$. Associating factors effecting the accessibility of patients to appropriate treatments are: place of residence, distance to the closet health facilities, types and severity of mentioned disorders. Conclusions: The prevalence of sinonasal diseases is significantly high in conducted location. In the coming years, the goverment of Soc Trang province needs to enact policies increasing the accessibility of people to local heathcare systems, ensuring the availability of appropriate healthcare services and strengthening communication methods of health education to raise people's understanding about the mentioned diseases.

Keywords: Diseases of the nose and sinuses, accessing medical examination and treatment services, health services.

\section{I. ĐẶT VẤN ĐỀ}

Các bệnh lý tai mũi họng khá phổ biến ở nước ta, ảnh hưởng đến sức khỏe. Các yếu tố ảnh hương tới bệnh lý TMH bao gồm kinh tế chậm phát triển, vệ sinh môi trường kém, nước thải, rác thải không được xử lý. Ô nhiếm môi trường, lao động nặng nhọc trong điều kiện chưa đảm bảo. Những thay đổi về vi khí hậu nơi ở, nơi làm 